\title{
Direito internacional humanitário e a atuação da Cruz Vermelha na América Latina
}

\author{
Alceu Cicco Filho ${ }^{1}$
}

\begin{abstract}
"Apesar de toda a boa vontade que move as ações de assistência humanitária, estas não deixam de ser ações em uma realidade perturbada."
\end{abstract}

Jean-Luc Chopard

\section{Resumo}

As ponderações ora tecidas se dedicam a explanar o Direito Internacional Humanitário e sua presença em países latino-americanos, sem olvidar, contudo, o louvável empenho do Comitê Internacional da Cruz Vermelha ${ }^{2}$ em difundir, nessas localidades, princípios humanitários. Em uma era marcada por atentados terroristas, massacres transnacionais e demais atos que minimizam e dilaceram a dignidade humana, sem dúvida emerge a necessidade de melhor entender as nuances do direito aplicado em tempos de conflitos armados, bem como as várias frentes de atuação do CICV, sua principal matriz. Nesse contexto, analisar-se-á sua disseminação em nações como a colombiana e haitiana, severamente vitimadas e dilaceradas pelo ímpeto sombrio de destruição humana, atentando-se com lealdade aos fatos históricos e às questões políticas que ocasionaram a ruptura do equilíbrio até então instituído e fizeram com que os Estados necessitassem do amparo do Direito Internacional Humanitário.

Palavras-chave: Direito Internacional Humanitário. América Latina. Comitê Internacional da Cruz Vermelha. Conflito armado.

${ }^{1}$ Graduando do 90 semestre de Direito do Centro Universitário de Brasília - UniCEUB. Pesquisador Bolsista do Conselho Nacional de Desenvolvimento Científico e Tecnológico - CNPq.

${ }^{2}$ Apenas a título de esclarecimento, cumpre ressaltar que com o escopo de evitar repetições e reprodução excessiva da expressão Comitê Internacional da Cruz Vermelha, optou-se por fazer em alguns momentos uso de sua forma abreviada, qual seja: CICV, termo este reconhecido pela instituição e largamente difundido em artigos científicos e em obras que retratam o tema. 


\section{Introdução}

Conflitos armados sempre acompanharam o ser humano no decorrer de sua existência, limitando-se o próprio ritmo da história ao relato de batalhas e às críticas de estadistas. Quiçá, por ser vista como "a mais brutal das manifestações humanas" (DISTEIN, 2004, p. 15), é indubitável que o seu estudo permeia, revolve e contorna a mente humana.

Se não havia outrora regulamentos ou mesmo preocupação para se limitar ou condicionar o uso da guerra nas relações internacionais (DUCREY, 1968) ${ }^{3}$, com o avançar das ideologias sociopolíticas, vigorou a pretensão de instituir mecanismos que regulassem a matéria ${ }^{4}$. Nesse sentido, com o Pacto Briand Kellog de 1928 e a Carta das Nações Unidas em 1945, individualizou-se a guerra como ilícito internacional, sagrando que todos devem:

Praticar a tolerância e viver em paz, uns com os outros, como bons vizinhos, e unir as forças para manter a paz e a segurança internacionais, e a garantir, pela aceitação de princípios e a instituição dos métodos, que a força armada não será utilizada a não ser no interesse comum, a empregar um mecanismo internacional para promover o progresso econômico e social de todos os povos ${ }^{5}$.

No mesmo sentido, o Tribunal Militar de Nuremberg asseverou que "uma guerra de agressão [...] é o supremo crime internacional [...] no qual contém em si todo o mal acumulado" (GREEN, 2000, p. 1, tradução nossa). ${ }^{6}$ Acrescentando lucidez a esse juízo, a criação do Tribunal Penal Internacional veio enfatizar que atos de agressão devem ser por todos recepcionados com grande repúdio, pois ainda que persista elevado grau de reprobabilidade pela comunidade internacional, conflitos armados na atualidade assumem novos contornos, alcançando índices maiores de vítimas que não raro são apagadas e pulverizadas com o ardor inerente à carnificina bélica. É nesse contexto que Leonardo Borges (2006, p. 3) leciona:

\footnotetext{
${ }^{3}$ Mesmo sem limitar a guerra, já havia na Grécia Antiga regramentos consuetudinários de respeito aos mensageiros e aos cadáveres, bem como neutralidade dos santuários e locais tidos como sagrados.

${ }^{4}$ No período romano surgiu o primeiro ideário para uma guerra justa, bellum justum, convertendo-se, a posteriori, no ba uarte do Direito Internacional.

${ }^{5}$ Preâmbulo da Carta das Nações Unidas.

6 "A war of aggression [...] is the supreme international crime [...] in that it contains within itself the accumulated evil of the whole".
} 
[...] é imprescindível que o direito, como fator regulador da vida em sociedade, volte-se para essa questão e crie mecanismos para mitigar o sofrimento humano causado por uma situação de conflito armado, ou, em outras palavras, que se proponha a 'humanizar' a guerra.

Apesar de conflitante tentar impor regras de humanidade em face de uma circunstância que em sua essência já é desumana, no caso concreto, a salvaguarda das frágeis vítimas do conflito se apresenta não só relevante, mas primordial. Dessa forma, o que anseia o Direito Internacional Humanitário não é conceituar e associar a guerra ao estado humano, tampouco que seus preceitos sejam pilares para que grupos beligerantes entendam a sua causa como proba, mas com simplicidade.

[...] se propõe a impedir que as partes em um conflito armado atuem com uma crueldade cega e implacável, e proporcionar a proteção fundamental que os mais diretamente afetados pelo conflito necessitam, sem que a guerra deixe de seguir sendo o que sempre foi, um fenômeno aterrador (KALSHOVEN; ZEGVELD, 2003, p. 12).

Não obstante haja o brocardo segundo o qual silent enim leges inter armes ${ }^{7}$, inegável é o caráter de essencialidade que recobre o Direito Internacional Humanitário, uma vez que ao impor aos entes em conflito limitações de ordem procedimental e instrumental, de certo modo luta para que as batalhas não se transformem em estado de barbárie absoluto, reinando o caos e a desordem descaridosa.

Na América Latina, por exemplo, o trabalho de difusão e aplicação do Direito Humanitário é realizado com louvável empenho pelo Comitê Internacional da Cruz Vermelha. Relatam que o corpo social se agoniza intensamente com as cicatrizes estigmatizadas em sua existência pelos conflitos armados e outras situações de violência, ressaltando que, em determinadas regiões, há quem ainda se esforce para resgatar a vida de outrora arruinada sem pesar por hostilidades cessadas há um lapso de tempo considerável (INTERNATIONAL COMMITTEE OF THE RED CROSS, 2008b).

Como breve passagem, nas suas várias atuações, o que mais aflige a Cruz Vermelha nos países latinos são as consequências humanitárias do conflito e da violência armada organizada, elevando a Colômbia à condição de protagonista em

7 "Leis são inoperantes em guerra". 
face de todo o esforço veemente e presteza arrebatadora do CICV no combate às atrocidades que desintegram o ímpeto de vida e existência humana.

Desse modo, a pretensão que se busca é a de explanar com maior profundidade e especificidade o desempenho do Direito Internacional Humanitário na América Latina, sobretudo como instrumento do Comitê Internacional da Cruz Vermelha de pacificar e amenizar os choques traumáticos advindos dessas formas cruéis e desonrosas de disputas transnacionais.

\section{Do direito internacional humanitário}

Se tivéssemos que em poucas linhas aclarar o Direito Internacional $\mathrm{Hu}-$ manitário, certamente o que delinearia a resposta seria sua lúcida atuação na minimização da dor e do sofrer causados com a guerra e as incessantes batalhas propagadas no âmbito internacional. Assim, como ramo do Direito Internacional Público, a essência do direito regulador dos conflitos armados acompanha o desenvolvimento social e se aperfeiçoa à medida que os modos de combate se mostram complexos, exorcizando suas sequelas nas mais remotas adjacências do universo humano ${ }^{8}$.

A história nos traduz que até o século XIX as soberanias envolvidas em conflitos firmavam acordos com o intuito de salvaguardar as frágeis vítimas oriundas daquela cruel subversão transnacional, mas tais pactos consubstanciavam uma data de vigência prefixada, perdurando unicamente naquele conflito que originou seu soerguimento.

Em face desses acontecimentos, o direito sentiu a vocação de tutelar atos de selvageria, não mais de forma pontual, específica, mas inovando ao instituir eficácia erga omnes com caráter duradouro, propagando-se a todos os sujeitos de

\footnotetext{
${ }^{8}$ Consoante o conceito elaborado pelo CICV, o Direito Internacional Humanitário define-se como "As regras internacionais, de origem convencional ou costumeira, que são especificamente destinadas a regulamentar os problemas humanitários decorrentes diretamente dos conflitos armados, internacionais ou não-internacionais, e que restringem, por razões humanitárias, o direito das partes no conflito de empregar os métodos e meios de guerra de sua escolha ou que protegem as pessoas e bens afetados, ou que podem ser afetados pelo conflito" cf. GASSER, 1993, p. 17.
} 
Direito Internacional Público que ratificassem e demonstrassem no cenário internacional a plenitude do respeito e da aceitação àquelas normas. Não obstante possuíssem a priori teor tímido, simbolizaram em 1864 o acolhimento do primeiro tratado intrínseco à matéria: a Convenção de Genebra, dedicada e ofertada a suavizar a sorte dos militares feridos em campanha.

À medida que sua validade e eficácia se propagavam, transmudava-se em novas fontes capazes de inibir o desempenho estatal em tempos de guerra, culminando com a formação de todo o arcabouço humanitário sistêmico tal como se apresenta no século XXI. Sua criação, por conseguinte, objetiva ser um óbice à plena atuação do ente público, condicionando e restringindo os mecanismos a serem utilizados em caso de enfrentamento armado, como também levando a cabo o manejo do pós-guerra e suas várias extensões.

3 Direito humanitário x direitos humanos: divergências e similitudes

Dentre as várias nuances que envolvem o tema, seguramente uma das mais expressivas e que nutre especial significância é a diferenciação entre Direito Humanitário e Direitos Humanos.

Com o término da segunda grande guerra e a nítida evidência do Holocausto, houve grande tentativa dos países de incorporar no ordenamento jurídico interno normas de direitos humanos, pilarizados em 1948 com a criação da Declaração Universal dos Direitos do Homem. Inseridos nessa frágil conjuntura, a inquietação dos internacionalistas se limitou a desvendar a correlação que paira entre os Direitos Humanos e o Direito Internacional Humanitário.

Após estudo minucioso e atento às varias facetas intrínsecas à matéria, constataram que as diferenças se iniciam na origem histórica. O DIH é relativamente antigo, ao passo que os regramentos de Direitos Humanos se apresentam de forma recente, porquanto foram sempre vistos como matéria de jurisdição interna (CANOTILHO, 1993, p. 517). No Direito Humanitário, entretanto, as normas estão contidas em tratados aos quais os Estados aderem voluntariamente, comprometendo-se não somente a respeitar seus mandamentos, mas também fazê-los acatados pelas demais soberanias que demonstraram no plano internacional aquiescência com o compromisso neles consubstanciado. 
Divergem, de igual modo, nos organismos que os promovem e operacionalizam; é dizer, a tutela dos direitos humanos conta com uma institucionalização tanto global, com fulcro nos ditames das Organizações Unidas, como regional, por intermédio da atuação do Estado em internalizar normas que prestigiem os direitos humanos (BUERGENTHAL; KISS, 1991) ${ }^{9}$, enquanto que o DIH encontra no Comitê Internacional da Cruz Vermelha seu principal expoente.

As diferenças se desmembram em outros vários matizes, alamedas que poderiam ser trilhadas se não fosse o interesse em acentuar o ponto central que distingue e torna límpida a autonomia dos referidos institutos: o DIH se faz presente em momentos de conflito armado, tutelando especificamente os agentes que estão sujeitos às atrocidades oriundas desse cenário devastador, um movimento armado que olvida o real motivo de sua presença e deságua na vítima as consequências de sua ingerência.

Nessa sistemática, o Direito Internacional Humanitário resguarda o corpo social das infrações graves de instituições do próprio Estado em conflitos armados de grupos ou indivíduos sob a égide de um comando responsável em situação de guerra, genocídio e atentados à humanidade. Os Direitos Humanos, ao seu turno, são aplicáveis em qualquer tempo ou lugar, não distinguindo a situação ou a origem da violação, se vinculada a conflitos armados ou à própria inércia do Estado face às garantias mínimas que permeiam o indivíduo (KOLB, 1998, p. 437-447).

Ainda há que se fazer referência à possibilidade das normas de Direitos Humanos serem suspensas na presença de circunstâncias que dificultem sua aplicação, casos em que as liberdades de locomoção, reunião e associação, por exemplo, são minimizadas em prol do interesse nacional ${ }^{10}$. A contrario sensu, as

\footnotetext{
${ }^{9}$ Cf. TRINDADE, 1991.

${ }^{10}$ Nesse tocante, interessante se atentar ao disposto no art. 4 do Pacto Internacional dos Direitos Civis e Políticos que assim dispõe: “Art. $4 \$ 1$. Quando situações excepcionais ameacem a existência da nação e sejam proclamadas oficialmente, os estados-partes no presente Pacto podem adotar, na estrita medida em que a situação o exigir, medidas que derroguem as obrigações decorrentes desse Pacto, desde que tais medidas não sejam incompatíveis com as demais obrigações que lhes sejam impostas pelo Direito Internacional e não acarretem discriminação alguma apenas por motivo de raça, cor, sexo, língua, religião ou origem social". Tem-se, igualmente, o art. 15 da Convenção Europeia e no âmbito regional o art. 27 da Convenção Americana de Direitos Humanos.
} 
regras de Direito Internacional Humanitário se fazem continuamente presentes, não possibilitando derrogações ${ }^{11}$.

Urge acrescentar a este diálogo acadêmico o que a doutrina classifica como Teoria da Complementaridade. Abordar as incongruências que revolvem o tema sem, contudo, elucidar seus pontos de convergência, certamente resultaria em um estudo falho, manco em suas diretrizes iniciais, pois mesmo que se tenha em mente a autonomia de tais segmentos, é indubitável que um faz uso dos preceitos inerentes ao outro para lograr o objetivo precípuo que os une: prestigiar o homem.

A teoria supramencionada reconhece a diferença no que tange ao regime jurídico a ser utilizado em cada oportunidade, mas admite o caráter complementar, tendo em vista que ambos possuem o mesmo referencial de proteção que é o indivíduo (HAMPSON, 1992, p. 117-127). Logo, prepondera a ideia de continuidade, não obstante a casuística ser, ressalvadas as devidas proporções, diferente.

Embora sejam sistemas normativos antagônicos, não seria de todo salutar pregar a inexistência de pontos conexos, como se vislumbra na salvaguarda da dignidade e do respeito à integridade física e moral do homem (MARTIN, 2001, p. 1037-1066). Para se fazer alusão à relevância do tema ora em apreço, as semelhanças existentes entre ambos os institutos impulsionaram as Organizações Unidas a ponderar e repensar sobre suas similitudes, como o fez na Conferência de Teerã acerca dos Direitos Humanos no final da década de 60, com o legítimo propósito de melhor salvaguardar o ser humano em sua essência ${ }^{12}$.

Outro aspecto intrínseco ao Direito Internacional Humanitário certamente se refere aos instrumentos que sufragam e legitimam sua atuação no cenário internacional. Seus alicerces são encontrados, com maior ênfase, nas Convenções e Pactos internacionais instituídos em 1949:

- A I Convenção de Genebra protege os feridos e doentes das Forças Armadas em campanha;

\footnotetext{
${ }^{11}$ Cf. Declaration of Minimum Humanitarian Standards. UN Doc. E/CN.4/SUB.2/1991/55.

${ }^{12}$ Passaram as Nações Unidas a se socorrer do Direito Internacional Humanitário como alicerce às suas resoluções. A título de exemplificação, tem-se a Resolução 688 do Conselho de Segurança em abril de 2005, justificando a aplicação do DIH no Iraque. Do mesmo modo, há a Resolução AG 1904 (XXXII-O/02), de junho de 2002, com o tema "Promoção e Respeito ao Direito Internacional Humanitário".
} 
- A II Convenção de Genebra protege os feridos, doentes e náufragos das Forças Armadas no mar;

- A III Convenção de Genebra protege os prisioneiros de guerra;

- A IV Convenção de Genebra tutela a população civil;

Momentos depois, em 1977, foram aprovados dois Protocolos adicionais a tais convenções:

- O Protocolo I reforça a proteção das vítimas de conflitos armados internacionais e amplia a definição deles às guerras de libertação nacional.

- O Protocolo II reforça a proteção das pessoas afetadas por conflitos armados internos, completando assim o Artigo $3^{\circ}$ comum às quatro Convenções de Genebra.

Evoluindo em consonância às necessidades sociais e ao novo modelo de realidade vivenciada no mundo contemporâneo, é inegável se afirmar que o Direito Internacional Humanitário permanece em expansão e desenvolvimento. Na década de 80, acolheu-se a Convenção das Organizações Unidas que se destinava a restringir o uso de certas engenharias bélicas nos conflitos armados, emergindo ainda tratados que se convertem com vivacidade em autêntico obstáculo ao uso de armas e táticas militares, entre os quais se tem a Convenção da Haia de 1954, que tutela o patrimônio cultural em tempo de conflito armado, a Convenção das Armas Químicas de 1993 e o Tratado de Ottawa sobre as minas antipessoais ${ }^{13}$.

Tendo em vista que não há como quedar inerte e insensível aos efeitos devastadores dos conflitos armados, ressurge como pilar da assistência humanitária o princípio da solidariedade universal, pois "o dever de ajudar aquele que necessita é um princípio inerente à própria natureza do homem: um princípio elementar e, ao mesmo tempo, ético, moral e religioso" (ZANGHI, 1999, p. 12).

\footnotetext{
${ }^{13}$ Mina antipessoal é munição concebida ou adaptada para explodir por meio da presença, proximidade ou mesmo contacto do agente com o material explosivo, destinando-se a colocá-lo fora de combate, ferí-lo ou matá-lo. Conceito nosso.
} 


\section{A Cruz Vermelha e suas frentes de atuação}

Em face de todo o panorama esboçado, cumpre enaltecer que o CICV atua como um dos principais protagonistas e incentivadores à aplicação do Direito Humanitário. Idealizada por Henry Dunant, há mais de cem anos de história, há mais de cem anos de solidariedade, sacrifício e altruísmo ao serviço da humanidade, desde sua primeira preocupação alicerçada no socorro dos feridos em guerra, a Cruz Vermelha testemunha um espírito de vanguarda na luta a toda e qualquer forma de sofrimento (CROCE ROSSA ITALIANA, 2008, tradução nossa) ${ }^{14}$. Segundo Mônica Teresa Costa Sousa (2007, p. 52),

Na segunda metade do século XIX acontece o que se pode chamar de "fato gerador" do moderno Direito Internacional Humanitário: o nascimento do CICV. Através da iniciativa de determinados cidadãos e do governo suíços, catorze delegados de países europeus presentes a uma Conferencia Internacional realizada em Genebra resolveram adotar um corpo de normas que vincularia os Estados em situações de conflito.

Fidedigna ao ideário de Dunant, "apaziguar todas as formas de sofrimento humano sem distinção de nacionalidade, raça, religião, de condição social ou de associação política" (CROCE ROSSA ITALIANA, 2008, tradução nossa) ${ }^{15}$, a Cruz Vermelha estende esse preceito a cada ação que, de alguma forma, recrute a altivez de suas engrenagens. $\mathrm{Na}$ América Latina, seu desempenho tem refletido grande comprometimento no incentivo às autoridades nacionais na ratificação de tratados e convenções internacionais, bem como na edificação de novos princípios minimizadores da excessiva impunidade nos casos tidos como crimes de guerra. Como exemplo, tem-se a reunião no segundo semestre de 2006, no Rio de Janeiro, de delegações representantes das dez sociedades nacionais da Cruz Vermelha na América Latina, objetivando definir, ou ao menos tracejar, as linhas de ação para ajuda humanitária no continente para os anos vindouros.

${ }^{14}$ Versão Original: "Più di cento anni di storia, più di cento anni di solidarietà, di sacrificio, di abnegazione, più di cento anni al servizio dell’Umanità. Dapprima volta al soccorso dei feriti in guerra, la Croce Rossa è oggi la più importante associazione umanitaria. Per la diversità delle azioni che sviluppa nel campo del soccorso, della salute e della solidarietà testimonia uno spirito all'avanguardia nella lotta a tutte le forme di sofferenza".

${ }^{15}$ Versão Original: "Fedele all'impegno del suo fondatore Henry Dunant, "placare tutte le sofferenze umane senza distinzione di nazionalità, di razza, di religione, di condizione sociale o di appartenenza politica" la Croce Rossa estende questo principio in ogni sua azione". 
Esse evento recrutou representantes da educação, saúde, desastres e desenvolvimento comunitário, com o escopo de propiciar um intercâmbio de informações que refletisse como um prisma na construção de planos regionais de trabalho, delimitando as diretrizes capitais e preliminares para posterior aplicação. Nesse contexto, o presidente do Comitê Regional Interamericano da Cruz Vermelha, Abel Peña, asseverou que os maiores desafios que dilapidam a ajuda humanitária no continente são a pobreza, a desigualdade social e a vulnerabilidade da população.

\subsection{Haiti}

O atual estágio de pobreza e esquecimento aos ensinamentos atemporais de direitos humanos no Haiti remonta momentos históricos essenciais para o entendimento dessa melancólica conjuntura.

A opressão que acompanhou a colonização de Santo Domingo e a exploração sem razoabilidade dos recursos haitianos pelo Estado colonizador, somado à violência desbravada do sistema escravocrata, ocasionaram em janeiro de 1804 na independência de um corpo social sofrido, maculado com os excessos de um despotismo desmedido e insensível aos limites do alcance humano. O sopro de um movimento libertário se fez necessário, pois o que estava a se perder era a identidade de um povo, o ímpeto de alvedrio calado pelos massacres e retalhado na opressão diária do regime colonizador. $\mathrm{O}$ ódio, como consequência, se tornou estrutural e predominou nos dois primeiros séculos da história haitiana. De fato, o primeiro governante haitiano fora militar, conduzindo o país a uma ditadura e posteriormente a grande maioria dos chefes de Estado ascendia ao poder por meio de intensos levantes como coup d'etat, guerras civis e revoltas, sendo relevante adicionar a essa horrenda tradição de violência as ocupações norte-americanas realizadas no decorrer dos trinta anos do regime ditatorial Duvaliers (1957-1986) e três anos de coup d'etat (1991-1994).

Cansada e devastada, no início da década de 90, a população haitiana delegou a Jean-Bertrand Aristide a função de edificar e soerguer a democracia; mas, ao assumir o poder, contribuiu ainda mais para o caos generalizado, o desrespeito à legalidade que se buscava legitimamente constituir, bem como aumentou o custo 
dos produtos essenciais à sobrevivência humana, polarizando a política e deteriorando a dignidade daqueles inseridos nesse apático contexto social ${ }^{16}$.

Após a sua derrocada, a crise social e política intrínseca ao Haiti fora minimizada, todavia longe está de se chegar ao seu término. A presença de tropas americanas, canadenses, chilenas e francesas no país perdurou até a resolução 1542, na qual o Conselho de Segurança das Nações Unidas exara entendimento em prol da formação de tropa de paz, denominada Minustah ${ }^{17}$, retirando o corpo militar estrangeiro e incumbindo Brasil, Chile, Argentina e Uruguai da missão de nortear e afastar a frágil soberania de novas crises institucionais que amplamente refletem e surtem efeitos nefastos no contexto social.

A atual situação haitiana ainda é delicada. A capital Porto Príncipe possui índices de desemprego que perpassam os $80 \%$, sendo ao mesmo tempo caracterizada por grandes contrastes na distribuição de renda. É um momento de efervescência com destino predeterminado à explosão. Com frequência o corpo social se retira às ruas em prol da vida, sai para protestar pelos elevados custos dos alimentos que triplicaram desde 2007, brada contra a fome e desnutrição que alcançam além-mar. Luta, igualmente, contra a Missão Minustah que pela Paz não fez paz, violando os direitos humanos com total e escandalosa impunidade, em flagrante contradição às diretrizes definidas pelo Conselho de Segurança das Nações Unidas.

Assim, nesse meio obscuro e distante do ideário de humanização, no qual impera e faz germinar candente desrespeito ao ser humano, comportando paradoxos tão fortes, a função que desempenha a Cruz Vermelha reveste-se de essencialidade para minimizar incoerências e reduzir as violações à integridade humana.

Em entrevista à Agência Brasil, Felipe Donoso (2008), chefe da Delegação do Comitê Internacional da Cruz Vermelha no Haiti, define a situação do país costeiro como frágil "o país objetivamente não tem nenhuma razão para dizer que os problemas acabaram: como possibilidades de enfrentamento, problemas políticos, violência, violação de direitos humanos. Isso levará tempo”.

${ }^{16}$ A Organização dos Estados Americanos, por meio das resoluções 806 e 822, exigiam a imediata captura e detenção dos colaboradores desse regime desmedido e absolutista, enfatizando a necessidade de ruptura dessa ordem política e avocando a solidariedade dos demais Estados no auxílio à edificação de novos contornos institucionais no Haiti.

${ }^{17}$ Sigla em francês para Missão das Nações Unidas para Estabilização do Haiti. 
Informou ainda que era evidente a direção ali tomada de ir em encontro a um conflito interno, fato este que mobilizou o CICV no tocante ao auxílio dos feridos de uma potencial guerra.

Surge, portanto, a oportunidade de continuar perseverando, prosseguindo com passos delicados e atentos às nuances do momento, às incertezas desse contexto, pois os elementos que instauraram a crise de outrora ainda perduram, sendo até mesmo difícil ousar esboçar o fim dessa longa era de transição. Donoso (2008) afirma que,

Durante esse período, um organismo como o CICV precisa estar muito atento. Não só como observador, mas de maneira bem ativa. Tomar todas as medidas preventivas para uma possível deteriorização da situação, mesmo que apenas em regiões específicas do país.

A função da Cruz Vermelha, nesse tempo de instabilidade, estende e prorroga-se aos estabelecimentos carcerários locais, já que prepondera a dificuldade de definir a linha tênue entre banditismo e violência política. Há uma superposição de problemas políticos com temas sociais e delinquência, assumindo caráter emergencial averiguar se os detentos ali se encontram por inobservância ao regramento criminal ou se por perseguição política.

Do mesmo modo, preocupa-se o Comitê não somente com a segurança da população civil em face da carência de forças armadas oficiais, extintas em 1995, mas igualmente com o excesso de tropas que operam de maneira concomitante e sem planos concretos de atuação como a Polícia Nacional, a Minustah, grupos armados, gangues e organizações populares armadas no decurso do tempo por intermédio de incentivos governamentais. Frente a tal dialética, o corpo social possui ínfimo amparo, transmudando-se em terreno fértil a germinar novos percalços políticos, violência e violação aos preceitos humanitários.

Revela a realidade haitiana um momento de perigo abstrato, imprevisível e sensível a qualquer tropeço por parte dos atores que se empenham na pacificação desses conflitos, vislumbrando-se aí a magna relevância consubstanciada nas atribuições do CICV. 


\subsection{Colômbia}

Os confrontos que perduram na Colômbia certamente podem ser vistos como resquícios da disputa pelo poder entre conservadores, liberais e socialistas na primeira metade do séc. XX. Os ciclos históricos narram que, com o advento da guerra civil, em meados de 1948, grupos liberais e socialistas foram impulsionados à união contra a etnia conservadora; tempos depois, em 1964, motivados pelo receio de radicalização da guerrilha camponesa, intensamente influenciada pela revolução cubana, grupos liberais romperam com a associação de outrora e se integraram a conservadores, subsidiando o envio de tropas ao povoado de Marquetália.

Com efeito, fugindo para regiões montanhosas e sob os auspícios do líder Manuel Marulanda, camponeses comunistas fundam as Forças Armadas Revolucionárias da Colômbia com o escopo de constituir um estado cujos pilares encontrassem arrimo nas teorias marxistas. Esse cenário aufere contornos mais nítidos quando outros segmentos de esquerda, e.g Exercito de Libertação Nacional, e milícias de extrema direita se inserem no conflito e nele agregam ainda mais disputa, inflamam o sentimento de revolta e dissipam morticínios.

Já na década de 80, outro ator é incorporado a esse deplorável panorama: o tráfico de drogas. As FARC-EP financiam a luta armada não somente por intermédio dos resgates oriundos do sequestro de civis, mas por meio da tutela e guarida a traficantes, sendo $78 \%$ de seu orçamento oriundo do narcotráfico (EJÉRCITO NACIONAL DE COLOMBIA, 2008). Cerca de sete mil pessoas foram sequestradas na última década (O FRACASSO..., 2008), sendo mais de três mil resgates pagos anualmente, afora as trinta mil vidas pulverizadas desde os anos 60. Somando a esse melancólico rol, a Human Rights Watch observa que 20 a 30 por cento dos combatentes das FARC são menores de 18 anos, ostentando 3500 guerrilheiros adolescentes (HUMAN RIGHTS WATCH, 2008).

Nesse esboço, a atividade do Comitê Internacional da Cruz Vermelha se destina à proteção e à assistência às vítimas do conflito armado. Do mesmo modo, o CICV se empenha em conferir respostas a agressões e conflitos armados pretéritos, mas cujas consequências remanescem e clamam por soluções, como o enclausuramento de pessoas e o resgate dos desaparecidos. 
Cumpre ressaltar que o trabalho exercido pelo CICV no País é o sexto maior do mundo, com várias frentes humanitárias em toda a nação ${ }^{18}$. Suas operações se caracterizam por suprir as necessidades humanitárias por meio da proteção e assistência, atuando com maior efetividade naqueles segmentos mais deteriorados com a guerra civil:

O CICV oferece, por exemplo, alimentos e utensílios domésticos de primeira necessidade às pessoas deslocadas durante os primeiros meses em que elas se encontram nesta situação, coordenando seu trabalho com os organismos encarregados de ajudá-las em seguida. Também melhora o acesso da população aos serviços de saúde, leva atenção médica preventiva e curativa, orienta os beneficiários para que eles usem os serviços públicos de saúde, acompanha os funcionários do Ministério da Saúde a regiões distantes, onde as condições de segurança são precárias, e implementa unidades móveis de saúde, com o apoio das Sociedades Nacionais parceiras (INTERNATIONAL COMMITTEE OF THE RED CROSS, 2008b).

De igual maneira, o Comitê Internacional da Cruz Vermelha visita os aprisionados nos estabelecimentos carcerários em todo o território colombiano com o propósito de averiguar as condições em que estão inseridos, bem como o tratamento a eles dispensado; insiste na visitação de militares e policiais capturados por grupos armados, com audácia luta pelo extermínio das minas antipessoais, prevenindo riscos e minimizando outros males; soma-se a este trabalho o constante auxílio às vítimas, bem como a integração com outros atores que se dedicam à extinção de acidentes e amparo às vitimas de minas e resíduos de explosivos de guerra.

Por fim, cabe ressaltar que o CICV também possui propósitos preventivos disseminados na Colômbia. Nesse viés, trabalha de forma concomitante com a Cruz Vermelha local, colabora na assistência individual aos deslocados, reunindo famílias apartadas com os conflitos e propagam o Direito Humanitário. É nesse

\footnotetext{
${ }^{18}$ Yves Giovannoni, chefe de operações do Conselho Internacional da Cruz Vermelha para América Latina e Caribe, afirma que "as principais características do conflito são a clara polarização e uma redução do espaço humanitário [...], provocando um maior sofrimento da população civil devido aos métodos empregados pelos diferentes atores armados na condução das hostilidades. Cf. INTERNATIONAL COMMITTEE OF THE RED CROSS, 2008a.
} 
cenário de instabilidade e nostalgia que as atividades do Comitê Internacional da Cruz Vermelha revelam seu fulgor, pois representam, talvez, o brilho isolado em momentos de guerra e fragilidade, tempos em que o homem, no seu ímpeto de dignidade, já não mais suporta as vicissitudes do instante e, por conseguinte, brada por socorro.

\subsection{Brasil}

No que concerne ao Brasil, este foi o primeiro Estado da América Latina a designar uma Comissão Nacional para a Disseminação e Implementação do Direito Internacional Humanitário. Ao seguir essa trajetória, cumpriu tanto a promessa de instituí-la, firmada na XXVI Conferência da Cruz Vermelha, como alcançou o compromisso de torná-la operacional, integrando com vigor o DIH nos treinamentos e manuais das forças armadas, não obstante ainda persista grande vazio de normas destinadas à população civil.

Indo ao encontro desse juízo, a materialização em 2004 da Comissão de Direito Internacional Humanitário serviu de instrumento para realçar a propagação no âmbito pátrio do DIH que, com receio, aflorava em ritmo tímido e, para além disso, contribuiu na adequação das leis nacionais às exigências internacionais. Enaltecendo essa passagem, o Estado brasileiro aderiu aos principais tratados de Direito Internacional Humanitário, demonstrando candente predisposição em acatar suas normas e incorporar seus ideários no regramento jurídico nacional. Destarte,

[...] uma das principais preocupações do CICV neste contexto é aumentar o conhecimento e o respeito ao Direito Internacional Humanitário (DIH), que, quando corretamente aplicado, representa proteção fundamental à vida e à dignidade das pessoas mais vulneráveis em situações de conflito armado.

\section{$[\ldots]$}

A promoção destas normas é realizada principalmente com público acadêmico, meios de comunicação, militares e autoridades. Para isso, o CICV realiza periodicamente cursos, apresentações, palestras, conferências, além de publicar e difundir materiais impressos e áudio-visual sobre sua história e suas atividades (INTERNATIONAL COMMITTEE OF THE RED CROSS, 2008c). 
No mesmo diapasão, o CICV se envolve na promoção do Direito Internacional Humanitário por meio do incentivo aos legisladores para que eles assumam compromissos no âmbito internacional, ora ratificando tratados que coíbam a disseminação de minas, ora implementando mecanismos que tutelem bens culturalmente significantes a dada sociedade em tempos de guerra, por exemplo.

Não raras vezes, a divulgação do DIH se destina às Forças Armadas. Para tanto, as escolas de instrução e aperfeiçoamento de militares se dedicam para que esse ramo do direito aufira grande relevância na formação de seus membros e passe a representar nova perspectiva e assuma outros contornos nas missões castrenses. Ainda nessa esteira têm-se as entidades policiais. Por meio de suas instituições o Comitê Internacional da Cruz Vermelha protagoniza seu maior projeto em terras brasileiras: o Programa de Difusão das Normas dos Direitos Humanos e dos Princípios Humanitários Aplicáveis à Função Policial, levado a cabo com o apoio do Ministério da Justiça.

Constituem também destinatários de extraordinária significância a sociedade civil, imprensa e universidades, atores fundamentais na difusão e propagação do Direito Internacional Humanitário. Nesse contexto, o Comitê Internacional da Cruz Vermelha adapta suas frentes de atuação ao protagonismo juvenil, buscando inserir e alastrar o DIH por intermédio da participação construtiva de jovens e setores da sociedade alocados em regiões severamente desgastadas e molestadas com a violência urbana:

No Rio de Janeiro, o CICV implementa de forma piloto um programa chamado Exploremos o Direito Humanitário (EDH), voltado para escolas públicas localizadas em áreas de vulnerabilidade social indicadas pela Secretaria de Educação local. A partir de noções básicas do Direito Internacional Humanitário, o programa propõe aos estudantes a discussão sobre formas de solucionar impasses e conduzir divergências levando em conta a existência de limites, tolerância e solidariedade, convidando os alunos a refletirem sobre estas questões em seu ambiente cotidiano e no mundo.

A cooperação com a Sociedade Nacional da Cruz Vermelha Brasileira, entidade filantrópica de trabalho voluntário, fundada em 1908 e baseada no Rio de Janeiro, também é uma das principais atividades do CICV no Brasil, como forma de fortalecer o Movimento Internacional da Cruz 
Vermelha e do Crescente Vermelho e sua capacidade de resposta a situações de emergência (INTERNATIONAL COMMITTEE OF THE RED CROSS, 2008c).

É dessa profícua análise que insurge a relevância do papel desempenhado pelo CICV nas localidades que embora não submersas em conflitos armados, certamente apresentam em sua estrutura fragilidades traduzidas nos dilemas políticos, refletidas na delicada conjuntura socioeconômica e nos incessantes conflitos culturais que assolam nações como a brasileira. Em meio a esse atordoado cenário, o CICV acende e amplia a divulgação do Direito Internacional Humanitário no âmbito nacional, prestigiando a ideia de que antes de amortizar o flagelo do pósguerra, sua função magna repousa e reside na manutenção da paz, impulsionando trabalhos preventivos que se coadunem com os ideários de paz disseminados ao longo dos anos.

\subsection{Atuação da Cruz Vermelha nos demais países latino-americanos}

Naqueles países latinos em que a guerra ainda não ousou mostrar o caráter aterrorizador de sua face, o Comitê Internacional da Cruz Vermelha atua com o mesmo empenho e brilhantismo, enaltecendo trabalhos que valorizem a ação preventiva de suas campanhas.

Nessas localidades, o CICV assessora e confere apoio aos governos na ratificação e aplicação de mecanismos internacionais concernentes ao Direito Humanitário, auxilia na feitura de legislações correlatas aos emblemas da Cruz Vermelha e do Crescente Vermelho, fomenta a dilação de normas penalizadoras dos temidos crimes de guerra e com generosidade e sempre fiel aos ensinamentos de seu criador, encontra-se constantemente atenta à questão dos desaparecidos, amarga angústia de quem vive.

Acrescentando dados aos comentários até então tecidos, cumpre ressaltar que o Comitê Internacional da Cruz Vermelha dedica aos jovens parcela significante de seus projetos, enquanto se insere na qualidade de protagonistas de um futuro ainda em construção. Temas ligados à violência e demais males que assolam a dignidade humana são preocupações do Comitê e resultam em programas como o Exploremos o Direito Humanitário, presente nas escolas por meio de cursos de 
capacitação aos docentes. Promove ainda a cultivação do DIH no calendário acadêmico de universidades e organiza palestras a todos aqueles que se interessam não somente pelo direito aplicado em tempos de conflitos armados, mas também na difusão dos princípios humanitários.

Para tanto, conta com o auxílio de nove escritórios que atuam em toda a América Latina:

Há uma delegação na Colômbia desde 1969 e outra no Haiti desde 1994, que se concentram nesses países. Existe ainda uma delegação regional na Cidade do México, de onde são coordenadas as atividades na América Central e nos países do Caribe de idioma espanhol; outra em Caracas, que se ocupa das atividades na Venezuela, no Suriname e nos países do Caribe anglófono; outra em Lima, para as atividades no Peru, Bolívia e Equador; e em Buenos Aires, para as atividades na Argentina, Brasil, Chile, Paraguai e Uruguai. Além disso, o CICV tem três escritórios, um na Cidade da Guatemala, outro em Porto Espanha e outro em Brasília. O orçamento previsto para 2008, para toda a região, é de cerca de 50 milhões de dólares americanos. No que diz respeito ao pessoal em serviço, temos 87 delegados expatriados e 407 funcionários locais (INTERNATIONAL COMMITTEE OF THE RED CROSS, 2008b).

Em face do exposto, não seria errôneo permitir-se concluir que o Comitê Internacional da Cruz Vermelha possui projetos humanitários destinados a todos os atores internacionais que compõem e integram o universo humano, desde os mais necessitados até as nações situadas nas mais longínquas zonas da natureza, ainda que não envolvidas em guerras, ter-se-á uma diretriz humanitária lançada em sua direção. O equívoco seria atrever-se a dizer que estão imunes a hostilidades, pois com a corrida bélica, exaltando-se e sendo possível ouvir o rugido do ódio ecoando pelos hemisférios, resta atestar que a contagem regressiva rumo à fulminação da vida se instaura sem direito à pausa e com ela dá-se início ao prazo de validade do planeta.

\section{Considerações finais}

A vedação legal à guerra, bem como o constante empenho pela conservação da paz são os pilares do arcabouço jurídico internacional, sendo nesse viés a legítima 
perspectiva de se estudar o Direito Internacional Humanitário (DIH). O seu objetivo de "preservar a humanidade perante a realidade da guerra é secundário: o primeiro desígnio deve evitar os conflitos armados" (KALSHOVEN; ZEGVELD, 2003. p. 238). Todavia, ainda que soe irônico e reflita irracionalidade, esse anseio não foi até então foco de observação e reverência pelos Estados soberanos, sendo manifesto que fazem uso de hostilidades e instrumentos que envenenam a grandeza humana como meio de lograr suas aspirações nas relações internacionais. Talvez seja nesse contexto que Leonardo Borges (2006, p. 137) profere:

A partir do momento em que a voz da razão se cala e as normas do direito internacional público são desrespeitadas, surge a necessidade de adotar um conjunto de regras mínimas com a finalidade de atenuar os efeitos malignos da guerra.

De tal modo, o que se deve buscar é harmonizar os conflitos militares à máxima de humanidade para viabilizar a perpetuidade da existência humana, sendo nesse cenário que se alicerça todo o esplendor e magnificência do Direito Internacional Humanitário. Suas normas e preceitos devem ser difundidos não somente quando a obscuridão aterrorizadora dos conflitos se impõe e se revela atual, mas também em momentos de paz e serenidade. No mesmo sentido, Pictet (1960, p. 581) exara entendimento segundo o qual o DIH

[...] deve ser amplamente disseminado entre a população para que seus princípios sejam conhecidos por todos aqueles que podem deles se beneficiar. É possível ir além, e dizer que os homens devem ser treinados desde a infância conforme os grandes princípios da humanidade e civilidade, a fim de que estes princípios criem raízes profundas em sua consciência.

É certo que a estrada é longa e, muitas vezes, apresenta obstáculos ilimitados, o mar se revela revolto e o ímpeto de esperança assoalha sua impotência, especialmente quando se relaciona com Estados que contemplam baixos índices de desenvolvimento, preponderando a desigualdade social e a falta de conhecimento generalizada, caso da América Latina. Se de um lado, por si só, não são as causas dos conflitos armados, por outro, criam o ambiente propício para sua expansão.

Temas como o cuidado que se deve proporcionar aos feridos em guerra, o advento de novos instrumentos e técnicas de combate, a possibilidade de se ter conflitos armados com recursos nucleares e o terrorismo de grupos armados 
paraestatais, tal como na Colômbia, são preocupações que concentram no Direito Internacional o dever de encontrar soluções e novas perspectivas para se preservar o indivíduo em sua plenitude (HARROFF-TAVEL, 1998, p. 5-20).

Seria possível indagar se a civilização representa a batalha entre o ímpeto de sobrevivência e o instinto de extermínio (BORGES, 2006, p. 137), pois é nesse cenário que toda a existência humana se alicerça: "a evolução da civilização pode ser simplesmente descrita como a luta da espécie humana pela vida" (FREUD, 1997, p. 81-82). Assim sendo, até o momento em que as páginas da história se revirarem descrevendo morticínios, conflitos armados, enquanto perdurar o ataque mútuo de semelhantes a semelhantes, impondo sofrimento até o último sopro de vida, ali se fará presente e se justificará o Direito Humanitário.

O objetivo, portanto, não é outro senão o de incentivar sua propagação, sempre atentando às necessidades locais e às peculiaridades de cada Estado, evoluindo agilmente com a precisão do momento, com o fervor das batalhas e o clamor de suas vítimas, almas desgarradas que buscam na obscuridão do instante um mínimo de paz e dignidade.

\section{International humanitarian law and the Red Cross performance in Latin America}

\section{Abstract}

The considerations written aim to explain the International Humanitarian Law and its presence in Latin American, emphasizing the laudable efforts of the International Committee of the Red Cross in spreading humanitarian principles in these localities. In a time marked by terrorist attacks, massacres and other transnational acts that minimize human dignity, emerge the need to understand even more the nuances of the law applied in times of armed conflicts and the performance of the ICRC, its main matrix. In this context, this article will examine how the IHL is spread in nations such as Colombia and Haiti, severely affected by the dark impetus of human destruction, describing with loyalty the historical facts and political issues that caused the disruption of the equilibrium set and made the States call the support of International Humanitarian Law. 
Keywords: International Humanitarian Law. Latin America. International Committee of the Red Cross. Armed conflicts.

\section{Referências}

BORGES, Leonardo Estrela. O direito internacional humanitário. Belo Horizonte: Del Rey, 2006.

BUERGENTHAL, T; KISS, A. La protection internationale des droits de l'homme. Strasbourg: Engel, 1991.

CANOTILHO, J. J. G. Direito constitucional. Coimbra: Almedina, 1993.

CROCE ROSSA ITALIANA. Informazioni generali. Roma, 2008. Disponível em: $<$ http://www.cri.it/informazioni.php>. Acesso em: ago. 2008.

DISTEIN, Y. Guerra, agressão e legítima defesa. São Paulo: Manole, 2004.

DONOSO, Felipe apud MILANI, Aloisio. Cruz Vermelha Internacional avalia que situação do Haiti ainda é "frágil" e "indefinida". Disponível em: <www.radiobras. gov.br/materia_i_2004.php?materia=197079\&q=1>. Acesso em: set. 2008.

DUCREY, P. Lê traitement des prisionnier de guerre dans la Grèce des cités: des origines à la conquête romaine. Paris: Boccard, 1968.

EJÉRCITO NACIONAL DE COLOMBIA. El tránsito de las FARC al narcotráfico. Bogotá, 2008. Disponível em:< http://www.ejercito.mil.co/index. php?idcategoria=96291>. Acesso em: dez. 2008.

O FRACASSO de Chávez. O Estado de São Paulo, São Paulo, jan. 2008. Disponível em: <http://www.estadao.com.br/estadaodehoje/20080106/not_imp104889,0. php>. Acesso em: dez. 2008.

FREUD, Sigmund. O mal-estar na civilização. Rio de Janeiro: Imago, 1997.

GASSER, H. P. Le droit international humanitaire. Genève: Institut Henry Dunant, 1993.

GREEN, L. C. The contemporary law of armed conflict. Manchester: Manchester University Press, 2000. 
HAMPSON, F. Using international human rights machinery to enforce the international law of armed conflicts. RDMDG, [S.1.], v. 31, 1992.

HARROFF-TAVEL, M. Promouvoir des normes visant à limiter la violence en situation de crise: un défi, une stratégie, des alliances. RICR, [S.1.], n. 829, p. 5-20, mars/avril 1998.

HUMAN RIGHTS WATCH. Colombia: armed groups send children to war. New York, 2008. Disponível em: <http://www.hrw.org/en/news/2005/02/21/ colombia-armed-groups-send-children-war>. Acesso em: dez. 2008.

INTERNATIONAL COMMITTEE OF THE RED CROSS. Colômbia: um conflito com alarmante número de violações ao Direito Humanitário. Geneva, 2008. Disponível em: <http://www.cicr.org>. Acesso em: ago. 2008a.

INTERNATIONAL COMMITTEE OF THE RED CROSS. O CICV na América Latina e no Caribe. Geneva, 2008. Disponível em: < http://www.icrc.org/web/ por/sitepor0.nsf/html/america-interview-030708>. Acesso em: dez. 2008b.

INTERNATIONAL COMMITTEE OF THE RED CROSS. O CICV no Brasil. Geneva, 2008. Disponível em: <http://www.cicr.org/Web/por/sitepor0.nsf/ htmlall/brazil? OpenDocument>. Acesso em: dez. 2008c.

KALSHOVEN, F.; ZEGVELD, L. Restricciones a la conducción de la guerra. Buenos Aires: CICR, 2003.

KOLB, R. Relations entre le droit internacional humanitaire et les droits del'homme. RICR, [S.1.], n. 831. p. 437-447, Sept.1998.

MARTIN, F. Application du droit international humanitaire par la cour interaméricaine des droits de l'homme. RICR, [S.1.], n. 844, p. 1037-1066, Dec. 2001.

PICTET, J. Commentary on IV Geneva Convention relative to the protection of civilian persons in time of war. Geneva: ICRC, 1960.

SOUSA, Mônica Teresa Costa. Direito internacional humanitário. 2. ed. Curitiba: Juruá, 2007.

TRINDADE, A. A. Cançado. A proteção internacional dos direitos humanos: fundamentos jurídicos e instrumentos básicos. São Paulo: Saraiva, 1991. 
ZANGHI, Cláudio. Fundamentos éticos e morais do direito à assistência humanitária. In: ZANGHI, Cláudio. $O$ direito à assistência humanitária: anais do colóquio internacional sobre o direito à assistência humanitária. Tradução Catarina Eleonora F. Da Silva e Jeanne Sawara. Rio de Janeiro: Garamond, 1999. 